\title{
Transformando experiência em conhecimento durante oficinas para uso de programas computacionais no contexto escolar
}

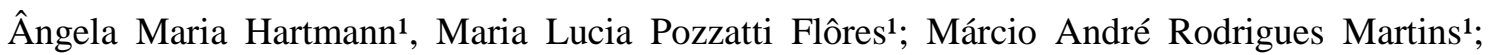
Rafhael Brum Werlangi; André Martins Alvarenga ${ }^{1}$; Anelise Marlene Schmidt ${ }^{1}$; Karine Halmenschlager ${ }^{1}$; Daniel da Silva Silveira ${ }^{1}$; Anelise Marlene Schmidt ${ }^{1}$; Guilherme Pacheco Casa Nova ${ }^{2}$

1 professores UNIPAMPA, campus Caçapava do Sul

${ }^{2}$ servidor UNIPAMPA, campus Caçapava do Sul

\section{Resumo}

Este artigo relata a experiência de um curso de formação continuada realizada por professores do campus Caçapava do Sul, da Universidade Federal do Pampa, com professores de escolas estaduais sobre o uso de programas computacionais no contexto escolar. A formação, baseada nos princípios da aprendizagem colaborativa, teve por objetivo (re)significar o conhecimento dos professores da Educação Básica a respeito da utilização de programas computacionais, refletindo sobre as possibilidades de seu uso para potencializar o processo de ensino e aprendizagem. Foram explorados seis programas computacionais, cada um configurando uma oficina de três horas de duração. Ao mesmo tempo em que exploraram o uso de programas computacionais, os professores da Educação Básica indicaram aos docentes do curso de Licenciatura em Ciências Exatas como elas podem ser utilizadas em sala de aula. Desse modo, os professores envolvidos aprenderam pela transformação da experiência em conhecimento ao interagir com a tecnologia computacional.

Palavras chave: Formação continuada. Aprendizagem colaborativa. Programas computacionais.

\begin{abstract}
The present article reports the experience of a continuing education course conducted by professors from campus Caçapava do Sul of the Universidade Federal do Pampa, in Southern Brazil, with state school teachers - on the use of computer programs in schools. The training, based on the principles of collaborative learning, aimed at (re)defining the teachers' knowledge of basic education regarding the use of computer programs. Six programs were used and examined in computing workshops of three hours each. While exploring the use of computer programs, teachers of basic education teachers indicated to the Bachelor of Mathematical Sciences how they can be used in the school context. Thus, the teachers involved learned about the transformation of experience into knowledge while interacting with computer technology.
\end{abstract}

Keywords: Continuing Education. Collaborative learning. Computer programs.

\section{Introdução}

A transformação da experiência em conhecimento pode ser descrita como um processo pelo qual o indivíduo reflete sobre sua experiência, fazendo emergir dela novas aprendizagens (KOLB, 1984). Visando promover reflexões sobre a prática pedagógica e, ao mesmo tempo, (re)significar o conhecimento de professores da Educação Básica quanto ao uso de programas computacionais na educação, um grupo de professores da Licenciatura em Ciências Exatas, da Universidade Federal do Pampa, promoveu, em julho de 2012, um Ciclo de Palestras e Oficinas para professores de escolas públicas da rede estadual da cidade de Caçapava do Sul. 
Durante o evento de formação continuada, que se estendeu por dois dias, foram realizadas, além de uma mesa temática, com palestras sobre aprendizagem colaborativa e uso de mapas conceituais, seis oficinas sobre possibilidades de uso de programas computacionais no contexto escolar e uma de experimentação em que foi usado um programa computacional para apresentação das informações. $O$ diálogo entre professores da Educação Superior e professores da Educação Básica, promovido durante a realização da mesa temática, e a metodologia adotada durante as oficinas visaram o aprender pela experiência, endossando assim, a visão de Kolb (1984) da possibilidade de transformação da experiência em conhecimento por parte dos dois grupos de professores.

Neste trabalho, relata-se como aconteceram as oficinas, destacando a avaliação dos professores a respeito de sua realização e importância para a formação profissional de docentes que atuam na Educação Básica.

\section{A utilização de programas computacionais no processo de ensino e aprendizagem}

Os Parâmetros Curriculares Nacionais (PCN) apontam diversas possibilidades para o uso de computadores em aulas da Educação Básica: 1) como fonte de informação; 2) como auxílio no processo de construção de conhecimento; 3) como meio para desenvolver a autonomia pelo uso de programas computacionais (softwares), que possibilitem pensar, refletir e criar soluções; e 4) como ferramenta para realizar certas atividades, tais como a criação de filmes, de slides, de polígrafos, de provas, de material didático de uma maneira geral (BRASIL, 2001).

A popularização da rede mundial de computadores (Internet) possibilita ao professor preparar suas aulas usando uma biblioteca virtual imensa como fonte de pesquisa, bem como repensar e ampliar os modelos pedagógicos conhecidos, pois ele pode ter acesso a bancos de dados com objetos de aprendizagem diversos, além de sugestões de aulas produzidas por outros professores. Propicia, ainda, a troca de experiências, de materiais didáticos, o esclarecimento de dúvidas, a busca de informações atualizadas sobre diversos assuntos, relatos de experiências, leitura de notícias, busca de softwares livres, etc.

O uso de softwares educacionais e a realização de pesquisas na Internet podem ser utilizados pelo professor como apoio ao ensino (VIDAL et al., 2002). Esses recursos, aliados à mediação do professor, ajudam os alunos na resolução de problemas, na experimentação e na análise de hipóteses, criando condições para uma aprendizagem contextualizada (KENSKI, 2003).

À medida que as tecnologias computacionais vão sendo incorporadas às atividades realizadas em sala de aula, as escolas necessitam oportunizar e incentivar a formação de seus professores para a integração natural do computador às atividades docentes. Corroborando com essa expectativa de benefício, Papert (1994) argumenta que a tecnologia contribui para proporcionar um ambiente mais favorável à aprendizagem, enseja a interdisciplinaridade, permite explorar a criatividade, promovendo novos contextos para a aprendizagem de cada aluno, ao mesmo tempo em que respeita seu tempo de aprendizagem.

O professor precisa observar, contudo, que os recursos computacionais em si mesmos não são suficientes para garantir uma ação educacional diferenciada, se seu uso não estiver claro e fundamentado em teorias pedagógicas. Segundo Oliveira (2005), além da necessidade de saber lidar com o computador, o professor deve entregar-se ao processo de construir para si mesmo um novo conhecimento, incorporando não somente os princípios desenvolvidos atualmente sobre o uso da informática na educação, mas, acima de tudo, passando pelas considerações teóricas sobre a aprendizagem que melhor 
explicam a aquisição do conhecimento cognitivo. Trata-se de dominar o conhecimento científico de uma maneira ampla e necessária para o seu próprio aprimoramento intelectual.

Ao usar os recursos computacionais, é importante que o professor conheça as possibilidades e potencialidades do computador para saber como lidar com essa ferramenta em sala de aula. Para isso, precisa adotar uma metodologia que torne a introdução da tecnologia computacional em uma formação benéfica para a sociedade e para o crescimento pessoal do aluno, tornando-o um sujeito crítico e criativo em uma sociedade cada vez mais informatizada.

$\mathrm{O}$ uso de recursos computacionais exige, na maior parte das vezes, de profissionais em educação, que não tiveram acesso a eles durante sua formação inicial, uma orientação que lhes forneça subsídios para promover aulas usando essas tecnologias. Essa orientação, que pode acontecer em cursos de formação continuada, tem por objetivo encorajar os professores a fazer um uso apropriado e intensivo do computador em suas aulas como uma ferramenta de apoio ao ensino. Por outro lado, aprofundar o conhecimento sobre programas computacionais requer tempo e dedicação, algo que nem sempre disponibilizam em seu afazer diário.

A formação continuada de profissionais da educação para o uso de recursos computacionais vem ao encontro do Artigo 67, da Lei de Diretrizes e Bases da Educação (LDB 9394/96), que destaca a valorização dos profissionais da educação e a garantia da formação continuada do educador. Valente (1993, p.22) endossa essa ideia quando afirma que:

\begin{abstract}
A formação do professor deve prover condições para que ele construa conhecimento sobre as técnicas computacionais, entenda por que e como integrar o computador na sua prática pedagógica e seja capaz de superar barreiras de ordem administrativa e pedagógica. Essa prática possibilita a transição de um sistema fragmentado de ensino para uma abordagem integradora de conteúdo e voltada para a resolução de problemas específicos do interesse de cada aluno. Finalmente, deve-se criar condições para que o professor saiba recontextualizar o aprendizado e a experiência vividas durante a sua formação para a sua realidade de sala de aula compatibilizando as necessidades de seus alunos e os objetivos pedagógicos que se dispõe a atingir.
\end{abstract}

A promoção de espaços formativos, que contribuam para uma maior aproximação do professor da Educação Básica com os recursos computacionais e que permita a discussão crítica do uso destes em sala de aula é, portanto, fundamental. Os processos de formação não devem se limitar, contudo, apenas ao debate acerca da incorporação dos programas computacionais na prática pedagógica, pois é necessário que o docente tenha clareza acerca dos limites e potencialidades destes recursos, assim como tenha condições de buscar uma melhor adequação entre conhecimento específico de sua disciplina e metodologias de ensino.

Baseados nos princípios da aprendizagem colaborativa, alguns dos professores "oficineiros" procuraram desenvolver durante as três sessões de oficinas situações de interação e troca de conhecimentos e experiências no uso de programas computacionais. Ao usar essa metodologia, esperavam exemplificar como usar os princípios da aprendizagem colaborativa em situações presenciais.

\title{
3 A aprendizagem colaborativa
}

Campos et al (2003, p. 26) definem a aprendizagem colaborativa como "uma proposta pedagógica na qual estudantes ajudam-se no processo de aprendizagem, atuando como parceiros entre si e com o professor, com o objetivo de adquirir conhecimento sobre um dado objeto". Assim, em um processo 
educacional baseado na colaboração, o foco passa a ser a aprendizagem em grupo, ao invés de uma aprendizagem baseada em uma perspectiva individual. "Quando os alunos trabalham em conjunto, isto é, colaborativamente, produzem um conhecimento mais profundo e, ao mesmo tempo, deixam de ser independentes para se tornarem interdependentes" (PALLOF; PRATT, 2002, p. 141).

A base da aprendizagem colaborativa está na interação e troca entre os alunos, com o objetivo de ampliar sua competência em apreender e elaborar conhecimentos. Para estudiosos como Hardin e Ziebarth citado por Campos et al (2003), a aprendizagem colaborativa baseada na Internet, por exemplo, deve aproveitar o que há de melhor na rede, que é a possibilidade da comunicação e cooperação entre as pessoas. Conforme Behrens (2002), o uso da Internet com critério pode se tornar um instrumento significativo no processo educativo como um todo, pois ela propicia a criação de ambientes ricos, motivadores, interativos e colaborativos.

Da mesma forma que em situações presenciais, para conduzir o processo ensino-aprendizagem em ambientes online de forma colaborativa, o professor necessita ter clareza dos aspectos que envolvem fazer com que os alunos possam interagir e realmente cooperar uns com os outros, com o objetivo de apreender e elaborar conhecimentos. A Internet pode ser uma ferramenta para a criação de ambientes motivadores, interativos e colaborativos, mas somente disponibilizar algumas ferramentas como o e-mail, chats, fóruns não significa que os alunos os irão compartilhar e estarão trabalhando com base na aprendizagem colaborativa. A ação colaborativa depende do projeto organizado pelo professor, da metodologia utilizada e do direcionamento pedagógico dado ao curso com o auxílio da tecnologia.

\section{0 processo formativo durante o evento}

Professores do Curso de Licenciatura em Ciências Exatas realizaram, com apoio da Coordenação Acadêmica do Campus Caçapava do Sul da Unipampa, nos dias 17 e 19 de julho de 2012, o I Ciclo de Palestras e Oficinas de Formação Continuada, com a temática Aprendizagem Colaborativa. Fizeram parte das atividades, oficinas de formação continuada sobre a utilização de programas computacionais no processo de ensino-aprendizagem e uma mesa temática sobre Aprendizagem Colaborativa.

A realização de oficinas sobre o uso de programas computacionais no contexto escolar foi sugerido por uma das diretoras que, ao procurar os professores da licenciatura, apontou a subutilização dos laboratórios de informática nas escolas devido às dificuldades dos professores em utilizar essas tecnologias.

Durante os dois dias em que aconteceu o evento, aproximadamente noventa professores da rede pública estadual participaram das sete oficinas em que foram exploradas possibilidades de utilização de programas computacionais em sala de aula. As oficinas foram oferecidas em períodos de três horas, sendo que algumas aconteceram três vezes durante os dois dias para tornar possível aos professores participarem de mais de uma. A escolha da oficina pelos professores era livre, limitada, apenas, pelo número de vagas. Foram elas: 1) Explorando a internet: Exercitando o Raciocínio Lógico Matemático; 2) Produção de Filmes Amadores com Movie Maker; 3) Edição de textos: explorando potencialidades e recursos do Word; 4) Uso de planilhas eletrônicas no contexto escolar; 5) Criando Slides no Office PowerPoint; 6) Mapas Conceituais como estratégia de ensino, aprendizagem e avaliação; 7) Discussão dos processos químicos e físicos em uma estação de tratamento de água (MINI-ETA).

No segundo dia do evento, foi realizada uma mesa temática em que três professores do Curso de Licenciatura em Ciências Exatas exploraram conceitos e princípios da aprendizagem colaborativa em uma conversa reflexiva com os professores 
de Educação Básica. Inicialmente, cada um dos professores fez uma discussão/reflexão sobre o tema proposto. No segundo momento, ocorreu um diálogo entre todos os participantes da sessão (docentes convidados e docentes em formação). Nessa oportunidade, alguns professores socializaram atividades com caráter colaborativo que estão em desenvolvimento nos seus contextos de atuação. Entre essas atividades estão o desenvolvimento de projetos temáticos nas escolas e a realização de oficinas de leitura e contação de histórias.

\section{Oficina 1 - Explorando a internet: Exercitando o Raciocínio Lógico Matemático}

Esta oficina foi dividida em dois momentos. Primeiramente, no laboratório de informática, foram abordadas questões relativas à internet, tais como: criação de redes sociais (orkut, facebook), de e-mails e de currículo na plataforma lattes. No início desta atividade, os professores foram questionados sobre o nível de domínio que cada um deles possuía sobre os tópicos que seriam abordados. Essa sondagem foi de suma importância para determinar o nível de abordagem durante a oficina "Explorando a internet".

Num segundo momento, foram propostos aos professores, problemas de Raciocínio Lógico Matemático, com o objetivo de exercitar seu raciocínio lógico e mostrar a eles atividades que podem ser trabalhadas com os seus alunos nas escolas.

\section{Oficina 2 - Produção de Filmes Amadores com Movie Maker}

A oficina teve como objetivo orientar os professores participantes a usar o Movie Maker ${ }^{1}$ para produção de vídeos amadores a partir de fotos e imagens gravadas em filmes por máquinas fotográficas e filmadoras. A condição para participar da oficina era trazer um notebook com uma versão instalada do software. Para realização da oficina, a professora ministrante preparou alguns slides para ir apresentando, passo-a-passo, cada uma das ferramentas do programa. A realização da oficina contou com a ajuda de duas alunas do curso de licenciatura, que tinham alguma familiaridade com o software.

O grupo de professores que participou da oficina, em cada uma das três sessões em que ela aconteceu, foi bastante variado. Alguns demonstraram ter bastante familiaridade com o uso do software, e participaram da oficina com o intuito de aprender mais sobre o uso de algumas ferramentas. Outros, no entanto, demonstravam não saber como usá-las ou mesmo localizar o software no computador. Alguns professores não foram avisados que era necessário trazer um notebook. Estes acompanharam a produção do vídeo ajudando aqueles que tinham sua própria máquina. Houve também alguns professores que trouxeram o notebook, mas o software não fazia parte dos aplicativos do sistema operacional. Essa situação foi resolvida na terceira sessão da oficina, quando se lembrou que uma versão do software poderia ser salva gratuitamente no computador, uma vez que havia, na sala, acesso à internet (por cabo).

A oficina foi realizada de forma dialógica, procurando-se conhecer as dificuldades dos participantes no manejo do software e ajudando-os a encontrar as ferramentas na barra de acesso. A oficina contemplou a aprendizagem colaborativa porque os professores, à medida que iam ganhando familiaridade com o programa, iam indicando aos colegas como usar as ferramentas para produzir os filmes.

\footnotetext{
${ }^{1}$ O Windows Movie Maker é um software de edição de vídeos da Microsoft. Atualmente faz parte do conjunto de aplicativos Windows Live, chamado de Windows Live Movie Maker (apenas disponível para Windows Vista e 7). É um programa simples e de fácil utilização, o que permite que pessoas sem muita experiência em informática possam adicionar efeitos de transição, textos personalizados e áudio nos seus filmes (Fonte: http://pt.wikipedia.org/wiki/Microsoft_Videos).
} 
Os filmes foram produzidos a partir de fotos que todos tinham em suas máquinas, especialmente, de familiares e, mais especificamente, dos próprios filhos. Também foram introduzidas trilhas sonoras, que tornaram as produções mais comoventes. Para concluir a oficina, os professores foram convidados a apresentar suas produções. Nesse momento, vários participantes se mostravam orgulhosos e satisfeitos, pois haviam entrado na sala sem conhecer o software e, em aproximadamente três horas, conseguiam manejar com criatividade suas ferramentas. $\mathrm{O}$ sentimento de realização pessoal, por ter aprendido a usar esse programa computacional era visível no semblante e se manifestava em agradecimentos à professora ministrante.

\section{Oficina 3 - Edição de textos: explorando potencialidades e recursos do Word}

Esta oficina teve por objetivo discutir com os professores da Educação Básica recursos de edição de texto do Word. Num primeiro momento, realizou-se um levantamento buscando identificar com os participantes: (i) o nível de domínio do Office Word; e (ii) se e como esse programa é utilizado na preparação e desenvolvimento de aulas. Essa discussão inicial indicou que a maioria dos docentes possui pouco domínio dos recursos do Word, sendo que alguns praticamente ainda não o tinham utilizado como ferramenta no planejamento ou o explorado em sala de aula como metodologia de ensino. Os professores que utilizavam o Office Word afirmaram que o faziam, principalmente, para preparar provas e digitar textos para reproduzi-los aos alunos. Alguns professores que desempenhavam atividades de coordenação e direção demostraram um maior conhecimento e também necessidade e interesse de explorar recursos mais avançados que a ferramenta proporciona.

Considerando essa diversidade, mas, ao mesmo tempo, um predomínio de docentes com baixo domínio do Office Word, foram trabalhados, no segundo momento da oficina, recursos básicos de edição de texto, por meio da dinâmica de construção de um texto coletivo, a partir de tema escolhido pelos participantes da oficina. Entre os recursos explorados estão: reconhecimento inicial das funções (localização dos recursos na tela inicial e identificação da versão em uso em cada computador); gerenciamento de dados (Criar pasta, salvar documento); configuração de página; elaboração e edição de texto (formatação fonte, alinhamento, marcadores, numeração, tabulação, copiar, colar, etc). Num terceiro momento, foram explorados recursos mais avançados como a construção e formatação de tabelas, inserção e formatação de figuras e construção automática de sumário, entre outros.

Os docentes que já dominavam esses recursos básicos foram orientados a perguntar sobre aspectos que tinham dúvidas. Essa interação contribuiu para o estabelecimento de um espaço de diálogo, em que os interesses dos participantes da oficina ajudaram a orientar o desenvolvimento das atividades. Por fim, realizou-se uma pequena reflexão acerca dos limites e potencialidades do uso de programas computacionais em sala de aula, em especial sobre como os recursos do Office Word podem auxiliar a prática pedagógica e na aprendizagem dos alunos.

\section{Oficina 4 - $O$ uso de planilhas eletrônicas no contexto escolar}

Nesta oficina foram abordados conhecimentos básicos sobre planilha eletrônica e de que maneira esta pode auxiliar os professores na prática pedagógica. Entre os recursos explorados estão: criação de fórmulas, elaboração de gráficos e outras funcionalidades básicas do editor.

Essa oficina foi voltada para professores de Matemática, mas houve a participação de professores de outras áreas do conhecimento. Desta maneira, esta oficina buscou analisar situações problemas envolvendo a construção de equações e funções do $1^{\circ}$ e $2^{\circ}$ 
grau, bem como foi proposta a criação de uma planilha que simulava o fechamento de notas dos estudantes.

Nesse sentido, observamos Tajra (2012, p. 19), quando se refere ao uso dos softwares de simulação e de programação, "são excelentes recursos computacionais que permitem o aprimoramento das habilidades lógica, matemática e de resolução de problemas". Nessa perspectiva, a partir da utilização do software Excel, possibilitou-se tornar as aulas interessantes e promover uma aprendizagem significativa.

\section{Oficina 5 - Criando Slides no Office PowerPoint}

Nesta oficina foram abordados conhecimentos básicos sobre a produção de apresentações de um determinado tema através do software Microsoft Office PowerPoint. Ela foi desenvolvida seguindo Kolb (1984), que afirma que as experiências de aprendizagem levam ao desenvolvimento, porque se dirigem a uma meta, um propósito específico de aprendizado.

Os temas desenvolvidos foram: definição e objetivo do PowerPoint; os comandos básicos e sua utilização; processo de como fazer slides; estrutura de uma apresentação; elementos a serem observados; conclusão de uma apresentação. Essa oficina iniciou com a experiência, seguida pela reflexão coletiva, discussão, análise e avaliação da experiência.

Foi possível trabalhar experimentalmente, pois a maioria dos professores participantes trouxe um notebook com Office instalado. O grupo de professores participantes era bastante heterogêneo, com alguns demonstrando bastante familiaridade com o uso do software, enquanto outros não. Por esse motivo, foi incentivada a interação entre o grupo que dominava o PowerPoint e os iniciantes e assim, a oficina teve sucesso, pois à medida que os professores dominavam o software, montaram apresentações sobre um tema por eles conhecido.

\section{Oficina 6 - Mapas Conceituais como estratégia de ensino, aprendizagem e avaliação}

Inicialmente, por meio de apresentação expositiva-dialogada, abordou-se o histórico e os fundamentos psicológicos e epistemológicos subjacentes aos mapas conceituais. Posteriormente, os participantes da oficina, reunidos em grupos de três componentes, construíram mapas conceituais utilizando o programa computacional Cmap-Tools v.5.04. Os mapas construídos foram apresentados ao grande grupo (toda a turma) e discutidos. O coordenador da oficina circulou entre os grupos, trocando ideias e esclarecendo dúvidas. O processo de internalização dos mapas conceituais possibilitou aos participantes da oficina analisar as conexões entre os conceitos, aceitos contextualmente. $\mathrm{O}$ coordenador fez suas intervenções com o objetivo de proporcionar uma ressignificação dos conceitos e a construção de uma nova versão do mapa conceitual. Durante a apresentação dos mapas conceituais, o coordenador e os participantes da oficina iam avaliando as dificuldades e os avanços no uso da ferramenta computacional. Finalmente, foram discutidas as vantagens do uso de mapas conceituais para o processo de ensino-aprendizagem e os possíveis problemas de seu uso no contexto escolar.

\section{Oficina 7 - Discussão dos processos químicos e físicos em uma estação de tratamento de água (MINI-ETA)}

A oficina teve por objetivo apresentar a professores de Ciências do Ensino Fundamental os processos físicos e químicos que ocorrem em Estações de Tratamento (ETA) de águas. Inicialmente, foi realizada uma apresentação com slides mostrando a estrutura de uma estação de tratamento de águas, bem como as etapas do processo. 
Foram apresentados aos professores os sistemas de coleta de água, os processos de floculação e os decantadores, e os processos de desinfecção das águas. Foram explicadas, também, as diferenças nas características das águas conforme a região. Neste ponto foi enfatizado o fato de que, no entorno do município, as águas naturais contém grande quantidade de calcário, devido à atividade mineradora e que necessitam de um tratamento adicional para correção da dureza.

$\mathrm{Na}$ etapa seguinte, os professores montaram uma miniestação de tratamento utilizando uma amostra preparada com água de açude contendo argila. Primeiro foi realizada uma avalição do $\mathrm{pH}$ da amostra através de papel indicador universal. Em seguida procedeu-se ao processo de floculação da amostra adicionando, sob agitação, sulfato de alumínio. Após 15 minutos de agitação, deixou-se a amostra em repouso para decantação do material floculado. Na etapa seguinte, os professores procederam à filtração simples da amostra através de funil de vidro e do papel de filtro qualitativo. Mediram, então, o pH do filtrado, concluindo o experimento fazendo uma comparação com o $\mathrm{pH}$ inicial da amostra.

Na última etapa da oficina, o coordenador da oficina mostrou aos professores os diferentes indicadores ácido/base utilizados para avaliação do $\mathrm{pH}$, bem como indicadores naturais que podem ser obtidos de materiais do cotidiano. Em seguida, procedeu-se a avaliação do $\mathrm{pH}$ de várias amostras como vinagre, suco de laranja, detergente, shampoo, leite de magnésia, etc. Percebeu-se grande interesse e participação dos professores, o que demonstra que a experimentação pode enriquecer os saberes adquiridos em teoria, sendo uma ferramenta fundamental para o ensino de Ciências em escolas públicas.

\section{Resultados}

No dia seguinte ao I Ciclo de Palestras e Oficinas de Formação Continuada foi enviado aos professores participantes, por e-mail, o link de um formulário online para que eles avaliassem as atividades desenvolvidas durante o evento. Vinte e três professores responderam esse questionário. Os dados desse questionário foram analisados estatisticamente e mostraram que $91 \%$ dos professores, que responderam o questionário, avaliaram o evento como "Bom" e "Muito Bom", conforme Figura 1.

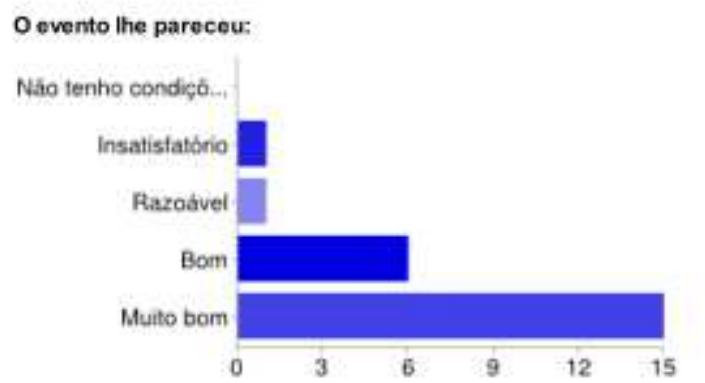

Figura 1 - Avaliação do evento pelos professores

O quadro 1 indica, com base em uma amostra de 23 professores respondentes, que, de um modo geral, as oficinas foram avaliadas como "Muito Bom". Destaca-se que cada professor poderia se inscrever em três oficinas. No entanto, nem todos os sujeitos que colaboraram com o questionário participaram de todas as atividades, como evidência-se no total de respostas.

Quadro 1 - Avaliação das oficinas de formação continuada 


\begin{tabular}{|l|c|c|c|c|c|}
\hline \multicolumn{1}{|c|}{ Oficina } & Insatisf. & Razoável & Bom & $\begin{array}{c}\text { Muito } \\
\text { Bom }\end{array}$ & TOTAL \\
\hline Oficina 1 - Explorando a internet & 0 & 0 & 0 & 6 & 6 \\
\hline Oficina 2 - Produção de Filmes Amadores & 0 & 0 & 2 & 8 & 10 \\
\hline Oficina 3 - Edição de textos & 0 & 0 & 5 & 6 & 11 \\
\hline Oficina 4 - O uso de planilhas eletrônicas & 0 & 1 & 2 & 3 & 6 \\
\hline Oficina 5 - Criando Slides no PowerPoint & 1 & 0 & 4 & 10 & 15 \\
\hline Oficina 6 - Mapas Conceituais & 0 & 2 & 3 & 4 & 9 \\
\hline Oficina 7 - MINI-ETA & 0 & 0 & 1 & 2 & 3 \\
\hline TOTAL & 1 & 3 & 17 & 39 & 60 \\
\hline
\end{tabular}

Os participantes do processo de formação continuada consideraram ainda que as oficinas foram receptivas e os ministrantes acessíveis, o que proporcionou momentos de intensa interação e diálogo. Conforme explicitaram em suas respostas ao questionário:

As professoras das oficinas foram receptivas e compreensivas, visto que havia pessoas sem notebook e com níveis de aprendizagem diferenciados.

As oficinas das quais participei foram práticas e vieram ao encontro das nossas necessidades, tiraram dúvidas e nos capacitaram um pouco mais.

Os professores ressaltaram em suas respostas a importância da interação Universidade-Escola, uma vez que atividades dessa natureza permitem compartilhar saberes e angústias em relação à atividade profissional. Isso, possibilita a (re)significação da prática docente, tanto do professor da Educação Básica quanto do Ensino Superior.

Uma consulta feita no formulário buscou conhecer qual seria o melhor período de realização desse tipo de evento de formação. Os professores que responderam o questionário indicaram o mês de julho como o melhor mês para o evento, que deve ter, na opinião deles, uma duração de até três dias. Os dias da semana indicados para sua realização são: quarta-feira $(29 \%)$, terça e quinta-feira $(22 \%)$, sexta $(13 \%)$ e segundafeira (12\%). Assim, os dados obtidos com o questionário contribuiram tanto para os oficineiros avaliarem as atividades desenvolvidas quanto para o planejamento de uma segunda edição do evento, de forma a atender melhor as demandas por formação dos professores da Educação Básica.

\section{Comentários Finais}

A avaliação dos professores e os relatos dos oficineiros indicam que é válida e atual a proposta de realização de eventos de formação continuada que tenham por objetivo (re)significar o uso de programas computacionais em situações de ensinoaprendizagem escolar. A constatação de que vários dos professores participantes não os utilizam em sua prática pedagógica por desconhecer sua potencialidade, apesar de as escolas possuírem Laboratórios de Informática, reforça a importância de tais cursos. Mesmo vivendo em uma época em que esses programas computacionais são de uso comum em várias outras situações profissionais, pode-se encontrar vários professores que não os utilizam em suas atividades docentes. Os softwares trabalhados nas oficinas são, a princípio, de fácil aprendizagem, mas percebe-se que as pessoas, de um modo geral, enfrentam duas dificuldades: 1) não ter tempo para aprenderem sozinhas a partir de um tutorial; 2) não estarem habituadas a buscar por si mesmas o conhecimento e se colocarem na dependência de alguém orientá-las durante a aprendizagem. 
Várias discussões/reflexões sobre aprendizagem colaborativa foram realizadas durante a mesa temática, após os participantes terem tido oportunidade de vivenciar nas oficinas situações em que essa metodologia foi colocada em prática. A interação entre professores da Educação Superior e professores da Educação Básica promoveu um aprendizado pela experiência para os dois grupos de professores. Geralmente, ao realizar um evento de formação continuada, os participantes imaginam que apenas eles aprendem com a experiência, mas essa aproximação mostrou que os organizadores também puderam aprender com o relato dos professores e suas dificuldades no uso de tecnologias computacionais. Em um processo recursivo, os professores da Educação Básica exploraram o uso de programas computacionais ao mesmo tempo em que indicaram aos docentes do curso de Licenciatura em Ciências Exatas quais são as dificuldades na aprendizagem e como elas podem ser utilizadas no contexto escolar. Desse modo, os professores envolvidos aprenderam pela transformação da experiência em conhecimento.

\section{Referências Bibliográficas}

BEHRENS, M. A. Projetos de aprendizagem colaborativa num paradigma emergente. In: Novas Tecnologias e Mediação Pedagógica. São Paulo: Papirus, 2002.

BRASIL. Secretaria de Educação Fundamental. Parâmetros Curriculares Nacionais: Introdução. 3. ed. Brasília: MEC/SEF, 2001. V.1.

CAMPOS, F. et al. Cooperação e aprendizagem on-line. Rio de Janeiro: DP\&A, 2003.

KENSKI, V. M. Novas tecnologias na educação presencial e a distância. In: BARBOSA, R. L. L. (org.) Formação de Educadores. São Paulo: Ed. UNESP, 2003.

KOLB, D. Experiential learning: Experience as the source of learning and development. New Jersey: Prentice-Hall, 1984.

PALLOF, R. M.; PRATT, K. Estimulando a Aprendizagem Colaborativa. In: Construindo Comunidades de Aprendizagem no Ciberespaço: estratégias eficientes para salas de aula on-line. Porto Alegre: Artmed, 2002.

PAPERT, S. A máquina das crianças: repensando a escola na era da Informática. Porto Alegre: Artes Médicas, 1994.

OLIVEIRA, E. M. Metodologia para o uso da informática na educação. Educação Matemática em Revista, n. 23, p.57-60, abr. 2005.

TAJRA, S. F. Informática na Educação: novas ferramentas pedagógicas para o professor na atualidade. São Paulo: Érica, 2012.

VALENTE, J. A. Formação de profissionais na área de informática em educação. Computadores e conhecimento: repensando a educação. Campinas, SP: Gráfica Central da Unicamp, 1993.

VIDAL, E. M. et al. Educação, Informática e Professores. Fortaleza: Edições Demócrito Rocha, 2002. 